\title{
Urinary trypsin inhibitor attenuates liver enzyme elevation after liver resection
}

\author{
Cheol-Won Jeong, Cha-Sup Lee, Seong-Heon Lee, Hye Jin Jeung, and Sang-Hyun Kwak \\ Department of Anesthesiology and Pain Medicine, Chonnam National University Medical School, Gwangju, Korea
}

Background: Urinary trypsin inhibitors (UTI) have been widely used for the treatment of diseases including disseminated intravascular coagulation, shock, and pancreatitis. Since UTI synthesis is likely to be reduced in patients who have undergone liver resection, the incidence of inflammatory reactions may be increasing accordingly. For such patients, the liver enzyme increases after the operation can reflect liver damage. The purpose of this study was to examine if ulinastatin can inhibit liver enzyme increases after liver resection.

Methods: After receiving Institutional Review Board approval, a retrospective chart review was performed on 201 patients who underwent hepatic resection from 2006 to 2010 . We divided the records into the control $(n=69)$ and ulinastatin $(n=132)$ groups according to the use of intraoperative ulinastatin and compared the preoperative and postoperative laboratory test results. The number of patients who had $>400 \mathrm{U} / \mathrm{L}$ elevation of aspartate transaminase (AST) level after surgery was compared between the 2 groups.

Results: The mean AST, alanine transaminase (ALT), and total bilirubin levels after liver resection were significantly lower in the ulinastatin group than in the control group. The number of patients who showed an AST > 400 U/L after liver resection was significantly higher in the control group (odds ratio $=3.02$ ).

Conclusions: Ulinastatin attenuates the elevation of hepatic enzymes and bilirubin after liver resection. (Korean J Anesthesiol 2012; 63: 120-123)

Key Words: Hepatectomy, Liver function test, Retrospective study, Ulinastatin.

Received: September 7, 2011. Revised: 1st, December 21, 2011; 2nd, January 30, 2012. Accepted: February 22, 2012.

Corresponding author: Sang-Hyun Kwak, M.D., Ph.D., Department of Anesthesiology and Pain Medicine, Chonnam National University Medical School, 42, Jebong-ro, Dong-gu, Gwangju 501-757, Korea. Tel: 82-62-220-6893, Fax: 82-62-232-6293, E-mail: shkwak@jnu.ac.kr (c) This is an open-access article distributed under the terms of the Creative Commons Attribution Non-Commercial License (http:// creativecommons.org/licenses/by-nc/3.0/), which permits unrestricted non-commercial use, distribution, and reproduction in any medium, provided the original work is properly cited. 


\section{Introduction}

Breakthroughs in surgical methods and anesthesia reduce mortality and morbidity in patients who have undergone liver resection. However, since a portion of a normal-functioning liver was resected in the course of surgery, the portion that remains becomes a major factor in assessing the risk of liver dysfunction after the operation [1]. Liver recovery after the operation would be affected by hyper-metabolic status and hyper-hemodynamic status after resection [2]. If various toxic substances accumulated in the body due to liver damage and cytokines were directly secreted into the circulatory system from the damaged liver, such a situation may worsen [3]. Moreover, the liver damage may be more severe due to activated leukocytes and proteases [4].

Ulinastatin, a protease inhibitor that is detected in urine and blood, was revealed to effectively reduce ischemic damage in multiple organs [5-7]. Ulinastatin administered during gastrectomy inhibited the increase of pro-inflammatory cytokines and can affect changes in liver function tests (LFT) [8].

In this study, we tried to assess the effects of ulinastatin through a tracking survey of LFT in the groups with and without ulinastatin, referring to the records of patients who had undergone liver resection.

\section{Materials and Methods}

This study was approved by the hospital Institutional Review Board. We retrospectively investigated the medical records of patients who had undergone liver resection during the period of January 2006 to June 2010 who were $31-79$ years old with American Society of Anesthesiologists (ASA) physical status I and II. All surgeries were performed by 3 surgeons, including liver wedge resection, liver lobectomy, and segmentectomy. It was confirmed by interviews with the surgeons that the surgical procedure and instruments being used remained unchanged. In the ulinastatin group, Hartmann's solution $1 \mathrm{~L}$ and Ulistin ${ }^{\circledR}$ (Ulinastatin, 100,000 IU/2 ml, Hanlim Pharm. Co., Ltd, Seoul, Korea) 300,000 IU were mixed and administered intravenously

Table 1. Patient Characteristics

\begin{tabular}{lccc}
\hline & $\begin{array}{c}\text { Control group } \\
(\mathrm{n}=69)\end{array}$ & $\begin{array}{c}\text { Ulinastatin group } \\
(\mathrm{n}=132)\end{array}$ & $\mathrm{P}$ \\
\hline Age (y) & $57 \pm 9$ & $58 \pm 9$ & $\mathrm{NS}$ \\
Sex (M/F) & $49 / 20$ & $100 / 32$ & $\mathrm{NS}$ \\
Body weight (kg) & $63.5 \pm 9.5$ & $63.5 \pm 9.8$ & $\mathrm{NS}$ \\
Height (m) & $1.64 \pm 8.58$ & $1.64 \pm 8.11$ & $\mathrm{NS}$ \\
Cirrhosis (yes/no) & $26 / 43$ & $53 / 79$ & $\mathrm{NS}$ \\
Hepatitis (yes/no) & $26 / 43$ & $60 / 72$ & $\mathrm{NS}$ \\
\hline
\end{tabular}

Data are expressed as numbers or mean \pm SD. during the operation. The laboratory data reached a maximum within 3 days after the operation and were analyzed. Cases of postoperative aspartate transaminase (AST) levels $>400 \mathrm{U} / \mathrm{L}$ were compared between groups. Cases of preoperative AST or alanine transaminase (ALT) level $>100 \mathrm{U} / \mathrm{L}$, serious systemic disease higher than ASA physical status III, and intraoperative transfusion of $>3$ units of red blood cells were excluded. Additionally, cirrhosis (yes/no) was defined by histologic evaluation.

The statistical program used in this study was SPSS 16.0 for Windows (SPSS Inc., Chicago, IL, USA) and the data are presented as numbers or mean $\pm \mathrm{SD}$. Comparisons between groups were performed using chi-square test or independent samples t-test. Odds ratio and $95 \%$ confidence interval were obtained from the comparison of both groups using the chisquare test to evaluate associations between elevated AST level $>400 \mathrm{U} / \mathrm{L}$ after surgery and infused ulinastatin during surgery. The difference was considered statistically significant when $\mathrm{P}<$ 0.05 .

\section{Results}

The total number of subjects was 201, including 132 in the ulinastatin group and 69 in the control group. There were no significant differences in sex, age, body weight, height, cirrhosis proportion, or hepatitis proportion between groups (Table 1). Operation type, time, and anesthetics are shown in Table 2. There were no significant differences in the operating times, kind of anesthetic agent used, and total number of left hepatectomies and liver wedge resections between groups. The number of patients who underwent right hepatectomy was significantly greater $(17.4 \%$ vs. $36.4 \%, \mathrm{P}<0.01)$ and segmentectomy was significantly smaller $(50.7 \%$ vs. $40.9 \%, \mathrm{P}=0.04)$ in the ulinastatin group.

Major complications included acute hepatic failure (1 patient in the control group and 3 patients in the ulinastatin group), and bleeding (2 patients in each group).

Table 2. Operation and Anesthesia

\begin{tabular}{lccc}
\hline & $\begin{array}{c}\text { Control group } \\
(\mathrm{n}=69)\end{array}$ & $\begin{array}{c}\text { Ulinastatin group } \\
(\mathrm{n}=132)\end{array}$ & $\mathrm{P}$ \\
\hline Operation type & & & \\
$\quad$ Left hepatectomy & $10(14.5 \%)$ & $17(12.9 \%)$ & $\mathrm{NS}$ \\
Right hepatectomy & $12(17.4 \%)$ & $48(36.4 \%)^{*}$ & $<0.01$ \\
Segmentectomy & $35(50.7 \%)$ & $54(40.9 \%)^{*}$ & 0.04 \\
Wedge resection & $12(17.4 \%)$ & $13(9.8 \%)$ & $\mathrm{NS}$ \\
Operating time (min) & $278 \pm 125$ & $285 \pm 107$ & $\mathrm{NS}$ \\
Anesthetics (propofol/ & $50 / 19$ & $107 / 25$ & $\mathrm{NS}$ \\
sevoflurane) & & & \\
\hline
\end{tabular}

Data are expressed as numbers (proportion) or mean $\pm \mathrm{SD}$. *P $<0.05$ compared with control group. 
Table 3. Laboratory Data

\begin{tabular}{lccc}
\hline & $\begin{array}{c}\text { Control group } \\
(\mathrm{n}=69)\end{array}$ & $\begin{array}{c}\text { Ulinastatin group } \\
(\mathrm{n}=132)\end{array}$ & $\mathrm{P}$ \\
\hline Pre-operative & & & \\
AST (U/L) & $36 \pm 22$ & $38 \pm 25$ & $\mathrm{NS}$ \\
ALT (U/L) & $36 \pm 29$ & $35 \pm 24$ & $\mathrm{NS}$ \\
ALP (U/L) & $105 \pm 66$ & $98 \pm 56$ & $\mathrm{NS}$ \\
PT (INR) & $1.05 \pm 0.12$ & $1.06 \pm 0.13$ & $\mathrm{NS}$ \\
Albumin (g/dl) & $4.7 \pm 5.91$ & $4.1 \pm 0.62$ & $\mathrm{NS}$ \\
T-bilirubin (mg/dl) & $0.86 \pm 0.48$ & $0.80 \pm 0.43$ & $\mathrm{NS}$ \\
Post-operative & & & \\
AST (U/L) & $189 \pm 173$ & $143 \pm 91^{*}$ & 0.04 \\
ALT (U/L) & $138 \pm 115$ & $105 \pm 73^{*}$ & 0.03 \\
ALP (U/L) & $79 \pm 37$ & $74 \pm 45$ & $\mathrm{NS}$ \\
PT (INR) & $1.25 \pm 0.27$ & $1.23 \pm 0.16$ & $\mathrm{NS}$ \\
Albumin (g/dl) & $3.34 \pm 0.51$ & $3.37 \pm 0.50$ & $\mathrm{NS}$ \\
T-bilirubin (mg/dl) & $1.93 \pm 1.62$ & $1.49 \pm 0.84^{*}$ & 0.04 \\
\hline
\end{tabular}

Values are expressed as mean $\pm \mathrm{SD}$. $* \mathrm{P}<0.05$ compared with control group.

No difference appeared in AST and ALT before the operation in either group, whereas they appeared to be significantly lower in the ulinastatin group ( $189 \pm 173$ vs. $143 \pm 91$ [P = 0.04], $138 \pm$ 115 vs. $105 \pm 73$ [P=0.03], respectively) (Table 3). Postoperative total bilirubin levels in the ulinastatin group were significantly lower than those in the control group $(\mathrm{P}=0.04)$. The number of patients whose AST levels in after operation increased to $>400$ $\mathrm{U} / \mathrm{L}$ appeared to be higher in the control group (odds ratio = $3.02,21.7 \%$ vs. $9.8 \%$ [P $<0.01]$, respectively, 95\% CI: $1.34-6.82$ ) (Table 4).

\section{Discussion}

After the liver resection, AST and ALT increased sharply, plateaued for 1-2 days, and then gradually decreased [9]. No explicit implication was made to state that these increases in AST and ALT were caused by liver damage. However, Whitehead et al. [10] reported that in cases of increased AST and ALT caused mostly by liver damage in patients with hypoxic liver damage, the AST value was $>400 \mathrm{U} / \mathrm{L}$. In this study, the average LFT after the operation appeared to be different, and the number of patients whose AST level was increased to $>400 \mathrm{U} / \mathrm{L}$ after the operation appeared to be clearly different between the 2 groups. Furthermore, serum total bilirubin values were significantly lower in the ulinastatin group. The increase in serum bilirubin after liver resection is likely related to parenchymal ischemia or inflammation [11]. This finding implied that it was difficult to judge that ulinastatin directly induced liver damage by liver manipulation, but ulinastatin could affect the increase of secondary metabolic or inflammatory AST and ALT after the liver resection. Studies have reported that, in case of
Table 4. Comparison of the Number of Patients with AST Levels > $400 \mathrm{U} / \mathrm{L}$ after Operation

\begin{tabular}{lccc}
\hline & $\begin{array}{c}\text { Control group } \\
(\mathrm{n}=69)\end{array}$ & $\begin{array}{c}\text { Ulinastatin group } \\
(\mathrm{n}=132)\end{array}$ & Total \\
\hline Positive $(\geq 400 \mathrm{U} / \mathrm{L})$ & $16(21.7 \%)$ & $12(9.8 \%)$ & 28 \\
Negative $(<400 \mathrm{U} / \mathrm{L})$ & $53(78.3 \%)$ & $120(90.2 \%)$ & 173 \\
Total & 69 & 132 & 201 \\
\hline & Odds ratio & P value & $95 \% \mathrm{CI}$ \\
\hline & 3.02 & $<0.01$ & $1.34-6.82$ \\
\hline
\end{tabular}

AST: aspartate transaminase, CI: confidence interval.

patients undergoing general abdominal operations and not liver resection, ulinastatin significantly inhibited AST and ALT increases after the operation, implying that it could be related to the inhibition of inflammatory cytokine increases [8].

Liver resection is a basic treatment for liver cancer; however, various side effects closely linked to liver failure may occur after the operation. Major factors causing such serious side effects are as follows: 1) cirrhosis or serious hepatosteatosis before the operation; 2 ) $<25 \%$ of the entire liver remaining; and 3 ) extensive ischemia-reperfusion injury occurring in the course of liver resection [12-14].

Ulinastatin is a urinary trypsin inhibitor that is detected in human urine and blood. The effect of ulinastatin is dosedependent [15]. In this study, 300,000 IU of ulinastatin, comparable to the $5,000 \mathrm{IU} / \mathrm{kg}$ administered in canine experiments, was administered [16]. Ulinastatin $6,000 \mathrm{IU} / \mathrm{kg}$ is considered the maximum safe dose because of its effects on coagulation and fibrinolysis [17]. In addition, the possible side effects of ulinastatin include nausea, vomiting, and hypersensitivity reactions, but the incidence is quite low at doses up to 300,000 IU/day [18].

Ulinastatin has anti-inflammatory and ischemia-reperfusion injury reduction effects $[6,18]$. Accordingly, ulinastatin is thought to affect not only ischemia-reperfusion injuries that can be caused by liver resection but also liver injury caused by inflammatory reactions. Nonetheless, as this study was retrospective in nature, it had limited indicators for liver failure, so it has certain limits, that is, it cannot help but use nonspecific variables such as increases in AST, ALT, or bilirubin.

In conclusion, ulinastatin is surely helpful in preventing liver resection-induced liver injury.

\section{Acknowledgments}

This study was supported by a grant (No. CRI10088-1) from Chonnam National University Hospital Research Institute of Clinical Medicine, Gwangju, South Korea. 


\section{References}

1. Schneider PD. Preoperative assessment of liver function. Surg Clin North Am 2004; 84: 355-73.

2. Ishikawa M, Nishioka M, Hanaki N, Miyauchi T, Kashiwagi Y, Miki $\mathrm{H}$. Hepatic resection induces a shift in the Th $1 / 2$ balance toward Th 2 and produces hypermetabolic and hyperhemodynamic states. Hepatogastroenterology 2004; 51: 1422-7.

3. Iwai H, Nagaki M, Naito T, Ishiki Y, Murakami N, Sugihara J, et al. Removal of endotoxin and cytokines by plasma exchange in patients with acute hepatic failure. Crit Care Med 1998; 26: 873-6.

4. Sauer A, Hartung T, Aigner J, Wendel A. Endotoxin-inducible granulocyte-mediated hepatocytotoxicity requires adhesion and serine protease release. J Leukoc Biol 1996; 60: 633-43.

5. Yano T, Anraku S, Nakayama R, Ushijima K. Neuroprotective effect of urinary trypsin inhibitor against focal cerebral ischemiareperfusion injury in rats. Anesthesiology 2003; 98: 465-73.

6. Kim SJ, Yoo KY, Jeong CW, Kim WM, Lee HK, Bae HB, et al. Urinary trypsin inhibitors afford cardioprotective effects through activation of PI3K-Akt and ERK signal transduction and inhibition of p38 MAPK and JNK. Cardiology 2009; 114: 264-70.

7. Chen CC, Liu ZM, Wang HH, He W, Wang Y, Wu WD. Effects of ulinastatin on renal ischemia-reperfusion injury in rats. Acta Pharmacol Sin 2004; 25: 1334-40.

8. Park JH, Kwak SH, Jeong CW, Bae HB, Kim SJ. Effect of ulinastatin on cytokine reaction during gastrectomy. Korean J Anesthesiol 2010; 58: 334-7.

9. Choi SJ, Gwak MS, Kim MH, Yang M, Ko JS, Hahm TS, et al. Differences of perioperative liver function, transfusion, and com- plications according to the type of hepatectomy in living donors. Transpl Int 2005; 18: 548-55.

10. Whitehead MW, Hawkes ND, Hainsworth I, Kingham JG. A prospective study of the causes of notably raised aspartate aminotransferase of liver origin. Gut 1999; 45: 129-33.

11. Chiarla C, Giovannini I, Giuliante F, Vellone M, Ardito F, Masi A, et al. Plasma bilirubin correlations in non-obstructive cholestasis after partial hepatectomy. Clin Chem Lab Med 2008; 46: 1598-601.

12. Schindl MJ, Redhead DN, Fearon KC, Garden OJ, Wigmore SJ. The value of residual liver volume as a predictor of hepatic dysfunction and infection after major liver resection. Gut 2005; 54: 289-96.

13. Mullin EJ, Metcalfe MS, Maddern GJ. How much liver resection is too much? Am J Surg 2005; 190: 87-97.

14. Truant S, Oberlin O, Sergent G, Lebuffe G, Gambiez L, Ernst O, et al. Remnant liver volume to body weight ratio > or $=0.5 \%$ : A new cut-off to estimate postoperative risks after extended resection in noncirrhotic liver. J Am Coll Surg 2007; 204: 22-33.

15. Xu L, Ren B, Li M, Jiang F, Zhanng Z, Hu J. Ulinastatin suppresses systemic inflammatory response following lung ischemiareperfusion injury in rats. Transplant Proc 2008; 40: 1310-1.

16. Tani T, Aoki H, Yoshioka T, Lin KJ, Kodama M. Treatment of septic shock with a protease inhibitor in a canine model: a prospective, randomized, controlled trial. Crit Care Med 1993; 21: 925-30.

17. Nishiyama T, Yokoyama T, Yamashita K. Effects of a protease inhibitor, ulinastatin, on coagulation and fibrinolysis in abdominal surgery. J Anesth 2006; 20: 179-82.

18. Park KH, Lee KH, Kim H, Hwang SO. The anti-inflammatory effects of ulinastatin in trauma patients with hemorrhagic shock. J Korean Med Sci 2010; 25: 128-34 